\title{
Novel Meander Line Slow Wave Structure for W-band TWT
}

\author{
Juan M. Socuéllamos ${ }^{1}$, Rosa Letizia ${ }^{1}$, Roberto Dionisio ${ }^{2}$ and Claudio Paoloni ${ }^{1}$ \\ ${ }^{1}$ Engineering Department, Lancaster University, Lancaster, United Kingdom \\ ${ }^{2}$ European Space Technology and Research Centre, European Space Agency, Noordwijk, The Netherlands
}

\begin{abstract}
The unfeasible fabrication of helix slow wave structures in W-band traveling wave tubes makes necessary to find alternative slow wave structures in order to amplify the RF signal to the output levels required to overcome atmospheric attenuation in satellite communications. Meander lines are nowadays being studied as slow wave structures for $W$-band traveling wave tubes due to their favorable properties compared to full metal alternatives. A novel meander line topology is introduced in this work, showing that high gain and output power can be achieved using a low-voltage electron beam. Cold and large signal simulations are presented in this work.
\end{abstract}

\section{INTRODUCTION}

$\mathrm{W}$ -BAND (71-76 GHz) may offer a suitable transmission window with relatively low atmospheric attenuation that will provide both high channel capacity and data transfer rate [1]. Yet the use of this band for satellite communications is so far prevented by the lack of power amplifiers. Traveling wave tubes (TWTs) are extensively used for satellite communications at microwaves and are able to provide tens or hundreds of watt. However, space TWTs are based on helix slow wave structures (SWSs) for the interaction beam-radiofrequency signal. Helix SWSs are not feasible at W-band due to the small dimensions. This has made necessary to find alternative slow wave structures for space TWTs [2, 3]. Meander lines are theoretically capable of providing similar gain and output power as full-metal SWSs while needing a much lower beam voltage $[4,5]$. This benefit, along with the suitability for lowcost and high-volume production, makes meander lines a promising SWS for W-band TWT.

This paper presents a novel meander line topology that provides peak gain and output power of $37 \mathrm{~dB}$ and $25 \mathrm{~W}$, respectively, while using a beam voltage of only $8 \mathrm{kV}$.

\section{RESUlts}

\section{A. Cold simulations}

The proposed new meander line (NML) is presented in Fig. 1. The novel meander line has been designed on alumina substrate with thickness $127 \mu \mathrm{m}$ and relative permittivity $\varepsilon_{\mathrm{r}}=$ 9.9 , and gold metallization with thickness $10 \mu \mathrm{m}$ and electric conductivity $\sigma=4.56 \times 10^{7} \mathrm{~S} / \mathrm{m}$. The simulations have been performed using the electromagnetic analysis software CST Microwave Studio [6].

The normalized phase velocity curve of the new meander line is presented in Fig. 2. The novel meander line is designed to interact with a sheet electron beam with voltage of $8 \mathrm{kV}$.

The interaction impedance curve for the new meander line is shown in Fig. 3. Within the $71-76 \mathrm{GHz}$ bandwidth, the new meander line offers an average interaction impedance of $2.6 \Omega$.

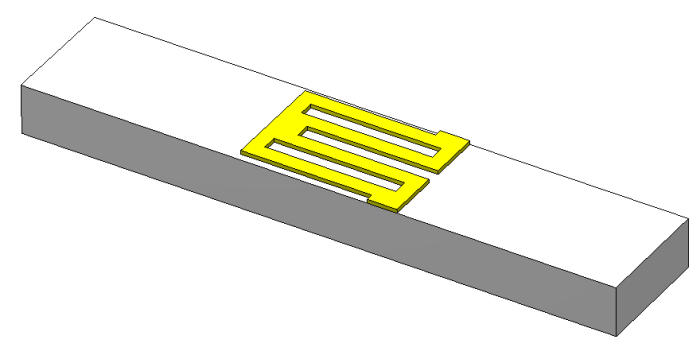

Fig. 1. Design of one period of the new meander line.

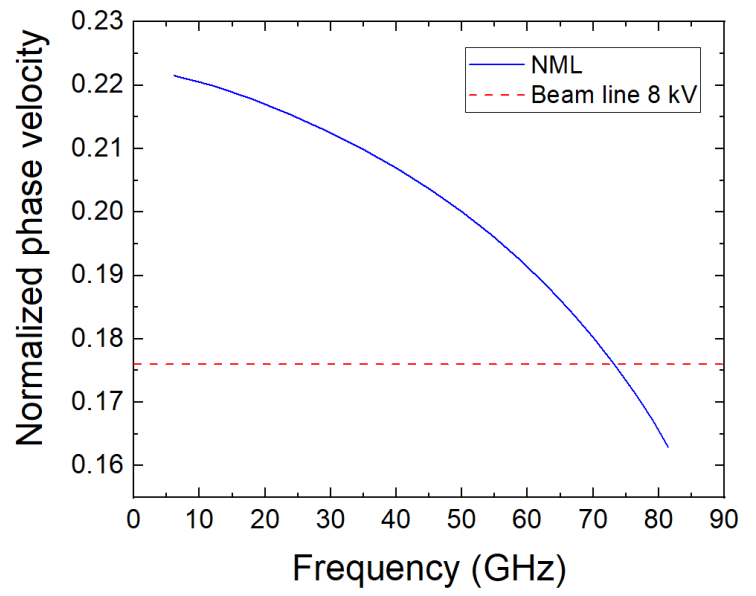

Fig. 2. Normalized phase velocity of the new meander line (blue solid curve) and beam line for $8 \mathrm{kV}$ (red dashed curve).

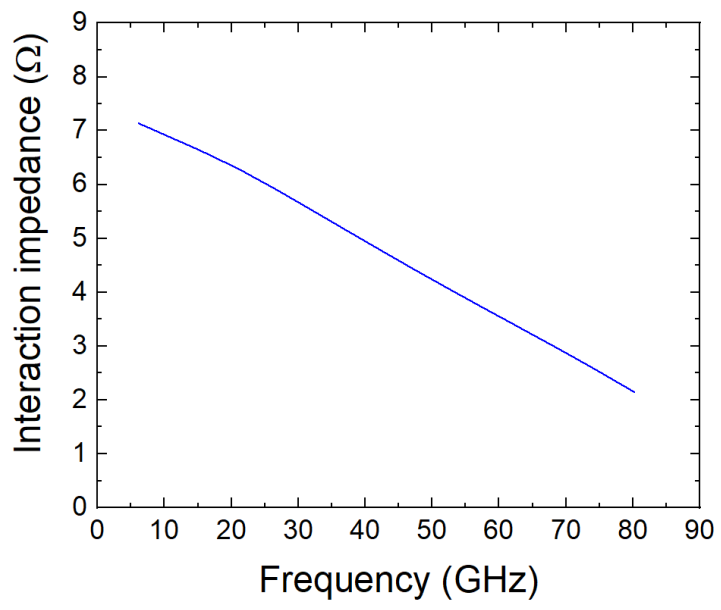

Fig. 3. Interaction impedance of the new meander line. 


\section{B. Full SWS simulations}

Large signal simulations are performed using a sheet electron beam with relatively low aspect ratio 2:1 where the greatest dimension equals the length of the novel meander line. The sheet beam is computed at a distance of $50 \mu \mathrm{m}$ from the metallization. The beam is focused with $1 \mathrm{~T}$ magnetic field for a current density of $160 \mathrm{~A} / \mathrm{cm}^{2}$. An input RF signal of $5 \mathrm{~mW}$ is applied.

Gain and output power results at $\mathrm{W}$-band $(71-76 \mathrm{GHz})$ are presented in Fig. 4. Gain and output power over $31 \mathrm{~dB}$ and 5 $\mathrm{W}$, respectively, are obtained for the whole 71-76 GHz band. Peak gain and output power reach $37 \mathrm{~dB}$ and $25 \mathrm{~W}$ at $75 \mathrm{GHz}$.

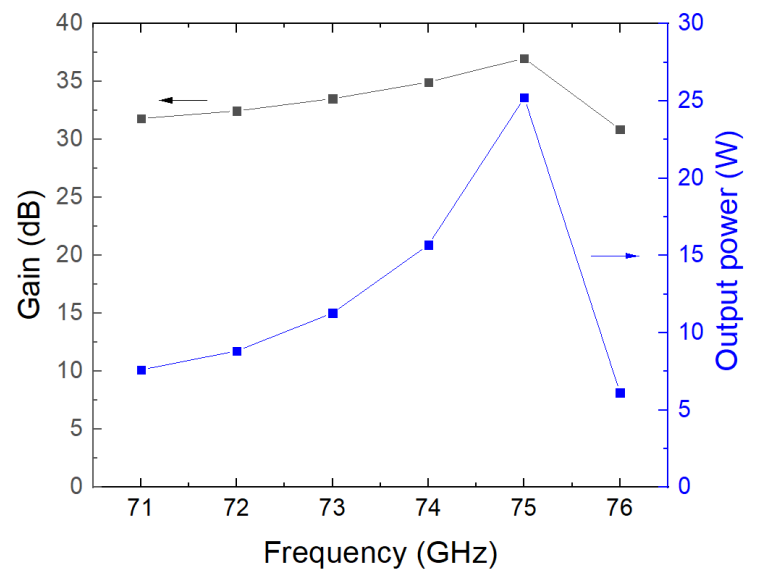

Fig. 4. Gain (black curve) and output power (blue curve) of the new meander line.

\section{SUMMARY}

A novel meander line topology has been designed and simulated at W-band. Cold results have shown that the novel meander line can operate with a beam voltage around $8 \mathrm{kV}$. The new meander line is capable of providing high levels of gain and output power while operating with a low beam voltage. The novel meander line represents a feasible alternative to helix slow wave structures and other full-metal slow wave structures for the production of low-cost, low-voltage W-band traveling wave tubes.

\section{REFERENCES}

[1] N. Ayllon, P. Angeletti, M. Ludwig and R. Dionisio, "An overview of European Spaceborne Vacuum Tube Amplifiers and System Needs", in Proc. IEEE $18^{\text {th }}$ Int. Vac. Electron. Conf., London, UK, April 2017.

[2] X. Li, X. Huang, S. Mathisen, R. Letizia, C. Paoloni, "Desing of 71-76 $\mathrm{GHz}$ Double-Corrugated Waveguide Traveling-Wave Tube for Satellite Downlink", IEEE Trans. on Electron Devices. vol. 65, no. 6, pp. 21952200, June 2018.

[3] C. W. Robertson, A. W. Cross, C. Gilmour, D. Dyson, P. G. Huggard, F. Cahill, M. Beardsley, R. Dionisio and K. Donald, "71-76 GHz Folded Waveguide TWT for Satellite Communications", in Proc. $20^{\text {th }}$ Int. Vac. Electron. Conf., Busan, South Korea, April 2019.

[4] J. M. Socuéllamos, R. Letizia, R. Dionisio, C. Paoloni, "Large Signal Analysis of a New Meander Line Topology for W-band TWTs", in Proc. $12^{\text {th }}$ UK/Europe-China Works. on mm-Wav. and Ter. Tech., London, UK, Aug. 2019.

[5] F. Shen, Y. Wei, H. Yin, Y. Gong, X. Xu, S. Wang, W. Wang and J. Feng, "A Novel V-Shaped Microstrip Meander-Line Slow Wave Structure for W-band MMPM", IEEE Trans. on Plasma Science, vol. 40, no. 2, pp. 463-469, Feb. 2012."

[6] CST-MWS. [Online]. Available: https://www.cst.com/products/cst. 